\title{
Ecological Worldview Formation of Engineering Students in the Context of Foreign Language Training
}

\author{
Maria Starovoitova \\ Institute of Humanities and Linguistic \\ Communications \\ Pskov State University \\ Pskov, Russia \\ mstarovoitova67@gmail.com \\ Elena Nikiforova \\ Institute of Humanities and \\ Linguistic Communications \\ Pskov State University \\ Pskov, Russia \\ trans7475@mail.ru
}

\author{
Svetlana Vodneva \\ Institute of Humanities and Linguistic \\ Communications \\ Pskov State University \\ Pskov, Russia \\ wodnewa@yandex.ru
}

\author{
Nadezhda Presnyakova \\ Institute of Humanities and \\ Linguistic Communications \\ Pskov State University \\ Pskov, Russia \\ presnyakovanadin@mail.ru
}

\author{
Tatyana Klets \\ Institute of Humanities and Linguistic \\ Communications \\ Pskov State University \\ Pskov, Russia \\ kte63@yandex.ru
}

\begin{abstract}
The educational space of a non-linguistic university makes it possible to conduct a purposeful process of forming the ecological worldview and culture of future specialists in the logic of their professional development. According to the authors, the eco-oriented content of teaching a foreign language can make a great contribution to the implementation of this mission due to the great general cultural and educational potential of this discipline. The paper offers a comprehensive theoretical substantiation of the problem under study, reveals the essence, structure and methodology of the ecological worldview formation of engineering students. The authors make an attempt to model the educational process on the basis of interactive pedagogical technologies, the use of which allows students of non-linguistic areas to solve communicative problems on the basis of environmental topics. The totality of data obtained as a result of the experimental work carried out by the authors confirms the effectiveness of students' ecological worldview formation through the inclusion of environmental-oriented content in the system of language training at the university.
\end{abstract}

Keywords - ecological worldview, engineering students, foreign language training, pedagogical technologies.

\section{INTRODUCTION}

Within the framework of the new paradigm of education for sustainable development, which is a new type of education that permeates all subject areas of natural, technical and humanitarian sciences, the content of university education is changing significantly. Environmental education, being a part of the content of higher education, is designed to solve the problems of the formation of an ecological information society and to reveal the main aspects of the interaction of people, society and nature. The main goal of environmental education of students is to form an environmental-oriented personality with developed ecological worldview. The issue of the formation of the ecological worldview of future specialists in the educational environment of a technical university is one of the urgent tasks of the higher education system in various aspects and in the training of all specialists. It acquires special significance in relation to the students of technical areas of training who, by their professional activities, exert the greatest anthropogenic load on the environment. In this regard, engineering students must receive a deep ecological background for successful professional activity [1], [2]. 
Obviously, the effectiveness of environmental education increases significantly with the integration of environmental knowledge into all possible disciplines, but a leading role in this process is played by the disciplines of the natural science cycle. Also, a special contribution to the formation of an ecological worldview and consciousness is made by subjects of the humanitarian cycle, including a foreign language.

However, when analyzing scientific and pedagogical literature, we came to the conclusion that there is an insufficient number of studies devoted to identifying the potential of the discipline "Foreign languages" for the ecological and professional development of engineering students and the development of methodological support for this process. In our opinion, a thorough study of this problem is very important and urgent.

Thus, the purpose of our research is to identify the features and content of the structural components of the ecological worldview and to describe the technology of working with engineering students in teaching English, aimed at developing an ecological worldview.

As theoretical research methods, we used the analysis of scientific and pedagogical literature on the problem and modeling the educational process for the development of an ecological worldview among engineering students within the discipline "Foreign languages". The empirical part of the study consists in generalizing the experience of applying interactive pedagogical technologies for teaching a foreign language, aimed at students' awareness of environmental problems, as well as in organizing, conducting, processing and interpreting the results of experimental teaching using methods of observation, interview, testing, questioning and analysis of students' products of speech activities.

\section{MATERIALS AND METHODS}

As mentioned above, environmental education, due to its relevance, is the subject of close study of specialists in various fields. Scientists agree that the main goal of environmental education is the formation of an ecological worldview among students and society as a whole, based on the unity of scientific and practical knowledge, a responsible and positive emotional-value attitude towards their health, the environment, improving the quality of life, and meeting human needs [3], [4], [5], [6]. Thus, an environmental worldview is becoming more and more in demand in society.

We understand by the ecological worldview of a future specialist, a graduate of a non-linguistic university, the integral part of his personality, based on ecological consciousness, ecological style of thinking and activities, which are projected onto his professional activity. Since the ecological worldview is part of the scientific worldview, it has the same aspects and components as the scientific worldview, but they are specific. The components of the ecological worldview include: 1) the system of socio-natural knowledge, 2) ecologocentric views and beliefs and their corresponding values and ideals, 3) skills and abilities of environmental protection, manifested in ecologically sound behavior, which is characterized by the transition of ecological knowledge, ecological thinking into everyday behavior.

Based on the above, we distinguish three main components of the ecological worldview: 1) cognitive, 2) axiological, and 3) activity. The cognitive component performs an explanatory and informational function of forming a worldview that corresponds to the modern level of science, historical practice and the intellectual requirements of students. The functions of the axiological component are to develop ideas about universal human and environmental values; development of the qualities of a cultural personality in young people in the field of relationships with nature. The functions of the activity component consist in the integration of the worldview and consciousness in practice, that is, in the process of interaction with nature; the formation of an active nature conservation and nature-creating position in the individual; practical environmental activities of future specialists.

As experts note, purposeful pedagogical activity on the formation of an ecological worldview and culture among future specialists during the period of study at a higher professional school can be considered as one of the best periods for such activities, since student age is considered the most sensitive for the development of reflexive abilities, understanding the world around students and their own place in it. In addition, the educational environment of the university is capable of providing a moral and developing atmosphere for the organic combination of professional and environmental consciousness, the assignment of the values of environmental culture and their translation into personal values and life guidelines [7], [8], [9].

It is obvious that the effectiveness of the ecological worldview formation increases significantly with the integration of environmental knowledge into all possible disciplines, mainly, in mastering the disciplines of the natural-scientific cycle.

It should be mentioned that environmental education is also reflected in the content of teaching a foreign language at a university and is expressed in an environmentally oriented training topics of a problematic nature. Taking into account the obligatory implementation of fragments of environmental education in a compulsory program, we can expect from students that they know the general terminology on the topic "environmental education" and possess the conceptual and categorical apparatus in this area.

In our opinion, in the context of the strategic goal of forming the ecological worldview of students, the main tasks of a foreign language teacher are: 1 ) the formation of 
sustainable motivation of students to environmental topics; 2) increasing the ecological and cultural level of students, 3) the formation of a student as an ecologically convinced personality in the human and professional sense; 4 ) optimal use of the content and educational potential of the discipline "Foreign languages" for the development of students' ecological lifestyle.

It should be emphasized that an effective means of implementing environmental education in foreign language training is the use of modern pedagogical technologies, such as game modeling, case studies, brainstorming, discussions, debates, project activities, etc. The use of modern educational technologies in the educational process develops the students' skills and abilities of systemic thinking, awakens in students the desire to search for new ideas, encourages creativity and collective interaction, contributes to the formation of readiness for their own optimal interaction with nature [10].

Within the framework of this research the English language teachers of the Department of Foreign Languages for Non-linguistic Areas of Pskov State University summarized the experience of using interactive technologies aimed at integrating environmental content into the language training of future engineers. In our activities with students of engineering educational programs we try not only to state the ecological problems that exist in their professional field but also make them contemplate over the actions they can do to escape or minimize them. Students' emotionally-colored reaction to the topics they argue about is success on the way to being ecologically aware.

Experimental training, carried out by the foreign language teachers, aimed at the formation of the ecological worldview of engineering students. The experiment involved 100 students of the Institute of Engineering Sciences of Pskov State University, enrolled in the following undergraduate programs: Construction, Informatics and Computer Engineering, Information Technology, Automobiles and Automotive Industry, Technosphere Safety, Electrical Engineering and Power Engineering, Mechanical Engineering.

The most relevant topics of environmental education were identified, based on brainstorming with students. These are some examples: "Can nature revenge people because of waste?”, "What can we do to save the planet?”, "Limited resources and unlimited wishes", "Promotion of renewable energies", "Employment sector of clean energies", "How much do we consume?”, "Pollution or economic stability”, "Ecotourism”, "Free-market environmentalism”, "Vehicle fuel economy standards".

In accordance with versatile environmental topics, preliminary work was carried out to master lexical units through didactic games (Domino "Matching ecological definitions", description of terms in pairs / groups, "Guess what I mean", compilation of mind maps, Word Bingo, Charades, Word Jeopardy, games to develop attention, memory and responsiveness - Pelmanism and Snap). In addition, Quizlet, Anki and Worditout applications were actively used.

A prerequisite was the use of speech and creative exercises in the process of studying environmental topics. Let us consider some examples of tasks and forms of work with environmentally friendly content: 1) Working with $a$ glossary "ecological problems", which lays the foundation for the further construction of speech exercises. 2) Making $a$ weather map. Students are invited to analyze climate change in a certain territory of Russia over the past 5 years, and then, taking into account individual data, draw up a climatic map of the country. 3) "Eco-projects fair". fulfillment of an individual project assignment on the history of charitable organizations for environmental protection. 4) Multimedia quiz "Are you ecological enough?" in which students test their knowledge on this topic and discuss ways to deal with the environment in a sustainable manner. 5) Presentation of modern energy saving technologies and renewable energy sources. 6) Environmental video journey "How climate affects architecture" introduces students to different types of architecture and the impact of climate on them. 7) Students' work on individual projects for the preparation of the Ecohouse exhibition. Students can describe existing green home options or suggest ideas of their own. 8) Debates "Do you agree with Greta Thunberg?"- the teams present their positions on climate change, political reshuffle and youth engagement in this context. 9) Ecological dilemmas (conversation cards) - students are invited to solve problems on an environmental theme with the choice of one of the options. 10) The game "Take a position" "Let's all go green", "Say no to plastic" - students need to determine their position and take an appropriate place in the discussion. 11) Discussions "Eco-cities should be built" and "How do you treat the Earth?"12) Sociological survey "How green are you?"13) Brainstorming "How ecology affects you?” 14) Role play "Why throw away? Why not recycle?"15) Discussion game "Sustainable / Unsustainable" during which students discuss a number of important topics for society (for example, vaccination, vegetarianism, etc.) from the point of view of a binary approach. This format contributes to the development of critical thinking skills and setting the vector for preparing for a debate. 16) Presentation "Climate behind headlines"- a selection of English-language articles on the topic of climate change, the discussion of the role of headlines and the effectiveness of eco-language in modern media.

Let us offer two fragments of lessons which aroused keen interest among students. Tables 1 and 2 illustrate the training organization algorithm in more detail. 
Table 1. Activity Algorithm of Project Work

\section{Project work \\ Students’ electronic waste recycling options}

1. Warming up: the mind map "Ecological problems in the sphere of IT Engineering”.

2. Group discussion (part 1): "What is E-waste?” Compare your definitions with those given in Britannica [https://www.britannica.com/technology/electronicwaste]. Are they different?

3. Group discussion (part 2): Why is it important to recycle E-waste? Is it illegal to throw away electronics? How should we recycle electronics? What are the disposal methods?

4. Read the article "E-waste disposal methods and how to do it?” [https://www.sellyt.com/blogs/e-waste-disposal/] and list the approaches towards eliminating electronic waste.

5. Watch TedTalk video "Recovering value: how I became an electronics recycler" [https://www.youtube.com/watch?v=sg18KmcTYXA] and answer the question "How did the speaker start her ewaste recycling company?"

6. Find the information about electronic waste recycling options at the university. Share the information with your project group.

7. Project work: develop electronic waste recycling options for students of your university and make multimedia presentation.

The second fragment of the environmental lesson was aimed at students of engineering educational programs with a language level of B2 (upper-intermediate). The lesson introduced learners to some of the main issues related to extended producer responsibility (EPR). The Extended Producer Responsibility (EPR) policy was first introduced by Thomas Lindhqvist in a report to the Swedish Ministry of Environment in 1990 [11]. A careful assessment of benefits of EPR is considered to be an important issue.

Table 2. Activity Algorithm of Project Work

\section{Students' project work on Extended Producer Responsibility Policy (EPR)}

1. Pair work: discussing the information about the companies known for their ecological responsibility; making a list of their activities and drawing a mind-map; brainstorming newly-acquired vocabulary.

2. Reading the article on EPR policy and making a list of conventional waste management techniques.

3. Group discussion "How do producers affect consumers? What are the rights and responsibilities of producers?” Sharing the information with other project groups.

4. Group work: brainstorming on how to design improvements of products and their systems, reuse or recycle them in an environmentally friendly and socially desirable manner.
5. Presentations of the best tips on the topic followed by general discussion.

6. Home assignment: project implementation on the topic "Policies used by the companies for promoting cleaner production” followed by a multimedia presentation.

By the end of the lesson students were able to 1) understand important causes of producer's responsibility and some solutions; 2) extend their understanding of lexis connected to environmental issues; 3) learn a number of simple collocations for talking about environmental issues as well as the use of speech patterns for giving advice and recommendations, use environmentrelated phrases, idioms and expressions of certainty when discussing events likely to happen.

Students focused on revising, learning and using vocabulary related to the environmental issues through a variety of engaging activities which helped them to improve speaking and listening skills. Activities also focused on reading and writing. The main emphasis was placed on the development of speaking skills. It should be noted that speaking activities are essential for English language classes, as students develop their communicative competence, become more versatile, fluent and adaptable. Being confident communicators in English is one of the most important skills, as these objectives for the students are written in each curriculum of university education.

\section{RESULTS AND DISCUSSION}

Let us consider the process of experimental teaching and analyze its main results. Experimental training included two stages. At the first stage, a survey of students called "Ecological awareness" was conducted. As it has been stated before, the formation of an ecological worldview is represented in three components: cognitive, axiological and activity level. In order to understand the level of ecological awareness and worldview of engineering students we have developed a questionnaire oriented on these components.

There were several criteria which affected the basis of the questionnaire: 1) for the cognitive component: understanding of the importance of ecological issues, the ability to highlight crucial problems in students' places of living; 2) for the axiological component: evaluation of self-readiness to improve ecological situation, estimation of social efforts in this field; 3) for the activity level: ability to perform ecologically oriented actions, take part in citizenship activities raising awareness of ecological problems. The questions were organized it three groups by the number of components under consideration: cognitive $(1,2,3)$, axiological $(5,6,9)$ and activity level $(4,7,8)$.

The questionnaire included the following questions: 1) How do you assess the environmental situation in your place of residence? 2) How do you assess the 
environmental situation in the world as a whole? 3) Do you consider yourself an environmentally responsible person? 4) Are you ready to show your civic position on environmental crimes, for example, when someone poisons the water or burns garbage in your neighborhood? 5) Do you think climate change affects people's health? 6) Can you name more than two ecological organizations that are familiar to you? 7) What activities can improve the environmental situation in your place of residence? Options for answers were: individual responsibility, civic participation in environmental issues, increasing the punishment for environmental crimes, involving managers of industrial enterprises in solving environmental problems. 8) How often do you sort rubbish in your household? 9) Do you consider your level of environmental awareness sufficient?

While conduction a survey we used the Survey Monkey platform: students received a link to the survey and passed it either in class or remotely. This approach is eco-friendly itself - you do not need to make a large number of printouts. The service we selected allowed us to analyze the answers of 100 respondents. We did not set the task of checking the level of knowledge regarding facts, figures and concepts in the environmental sphere, since, firstly, this material is in any case presented in the course of practical lessons in a foreign language, and secondly, it was the personal attitude to environmental issues that allowed for us to form a methodological component of classes with the implementation of environmental topics more specifically.

During the second stage, based on the results of the survey, an algorithm was developed for working with students using interactive forms and methodological techniques for the formation and development of students' awareness of environmental problems. In the course of the second stage, a list of some topics of current relevance was identified. Then, during one semester, students were taught using interactive technologies, some examples of which we presented above.

The training was intensive in nature and focused on the formation of environmental awareness, consciousness, culture and, as a result, was supposed to contribute to the development of the ecological worldview of students. At the end of the experimental training, we conducted a second survey of students based on the questionnaire that we used at the initial stage. Then we carried out a comparative and statistical analysis of the survey data at the initial and final levels. Our goal was to see the difference in numbers, and, therefore - in students' attitude towards ecological topics.

Let us present a general analysis of the questionnaire results. When assessing the ecological state of their region, the number of students who defined it as rather satisfactory increased by $20 \%$ at the end of the experiment. This increase indicates a deeper and more correct evaluation of the region's environmental problems by the students at the final stage of the experimental teaching.

In the process of discussing environmental issues, students became more critical of the overall assessment of the environmental situation around the world. Therefore, the number of respondents assessing the environmental situation in the world as generally unsatisfactory increased by $18 \%$ at the final stage. The increase in positive answers to the question "Do you consider yourself an environmentally responsible person?” was also significant. $21 \%$ more students responded that they consider themselves environmentally conscious and responsible and can personally affect the environment. Answering the question "Are you ready to show your civic position on environmental crimes?" 23\% of students changed their initial opinion about the correctness of noninterference at the sight of committing environmental violations and recognized the need for an active prevention of environmental crimes. As a result of project work during the experimental training the majority of students enlarged their knowledge of ecological organizations and recognized the need for sorting rubbish in the household (the increase is $15 \%$ and $17 \%$ respectively). The students positively assessed all the options that can improve the environmental situation in their place of residence. But it should be noted that the number of students who considered individual responsibility to be the most important has increased by $11 \%$. A $13 \%$ increase in the number of respondents who prioritized civic participation in environmental issues was also defined.

The answers to the question "Do you consider your level of environmental awareness sufficient?" showed the following results: at the beginning of the experiment: $25 \%$ of respondents answered "Definitely, yes", "Rather, yes" - 34\%; "Rather, no" - 20\%; "Definitely, no" - 21\%. At the final stage: $52 \%$ of respondents answered "Definitely, yes", "Rather, yes" - 34\%; "Rather, no" - 14\%; "Definitely, no" - $0 \%$. These significant changes in the assessment of the formation of environmental awareness, made by the students themselves as a result of environmentally oriented teaching, testify to the effectiveness of the selected environmental content and teaching technologies aimed at environmental education of students.

The answers in questionnaire were stated in comparison with the ecological worldview component levels: "Definitely, yes" - highly developed components, "Rather, yes" - medium developed components, "Ratner, no” - low level. "Definitely, no” - pretty low level.

The results of the statistical analysis of the initial and final data based on the survey results are presented in Fig. 1 and 2. We can state a significant increase in indicators corresponding to the levels "highly developed" and 
"medium”, as well as a decrease or disappearance of responses indicating a low and pretty low level. The most pronounced are positive changes at the cognitive and axiological levels, which indicate deep positive transformations in the minds of students that have occurred at the level of understanding and assessing the importance of environmental issues for ensuring sustainable development of society. Thus, the style of professional environmentally sound activity is manifested in a future engineer in a stable set of environmentally sound professional views, moral principles established by a specialist in the course of his work.

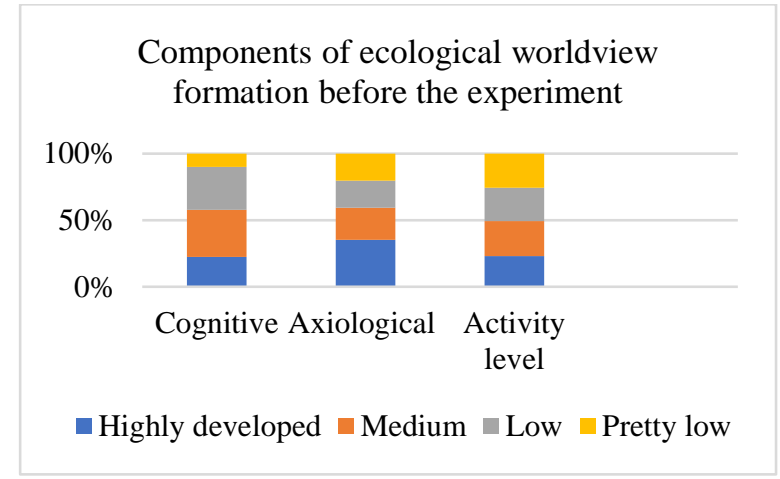

Fig. 1. The results of evaluating the level of ecological worldview development at the initial stage.

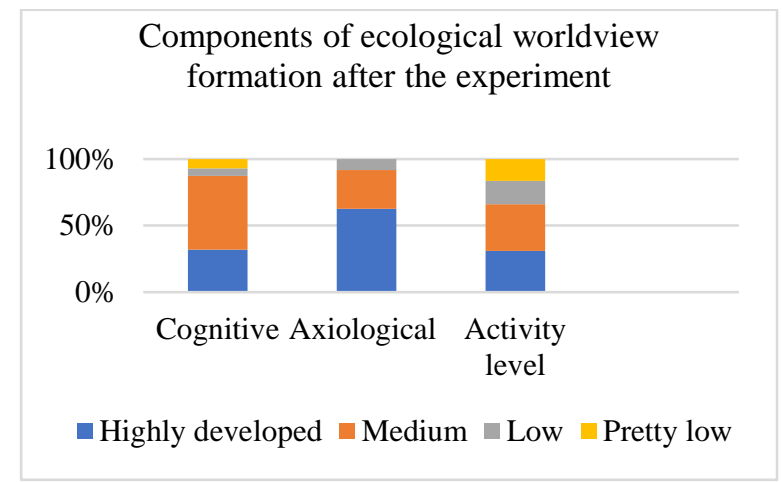

Fig. 2. The results of evaluating the level of ecological worldview development at the final stage.

In the course of a reflexive analysis of the results of experimental teaching, students identified the main characteristics inherent in a person with an ecological worldview, namely:

- conscientious observance of eco-oriented moral and ethical principles, attitudes, rules and skills of natural behavior;

- possession of environmental awareness, which involves the acquisition of environmental values that become life guidelines;

- a creative approach to organizing one's life with the maximum realization of one's natural abilities and inclinations, the choice of an eco-friendly life strategy.

Taking into account the results obtained, it can be concluded that the issues of environmental safety can and should be successfully integrated into the subject content of the language training of engineering students. At the same time, a foreign language teacher implements, in addition to an educational function, an upbringing function, and creates conditions for further study of environmental aspects in the professional activities of students.

\section{CONCLUSIONS}

Summing up, it should be noted that environmental education is designed to form a socio-ecological worldview of undergraduate students. The fact that a future engineer has an ecological worldview means that in his professional activities he will use resource-saving technologies, will strive to harmonize his relations with the environment, make professional decisions that would cause minimal harm to the environment. Thus, the ecological worldview is harmoniously embedded in the professional culture of the future specialist, complements and enriches it.

A foreign language can serve as a tool for educating an environmentally oriented engineering student who is aware of the interdependence of the world and the need for international cooperation in solving global problems of mankind. Accordingly, in the subject content of a foreign language at the university, more and more attention is paid to the problems of forming the ecological thinking of students, they are offered various tasks related to both the problems of environmental protection of nature and the ecology of relationships between people.

Experimental learning based on eco-oriented content using effective interactive pedagogical technologies, carried out by the authors of this study, showed obvious positive dynamics in the development of the ecological worldview of engineering students.

\section{REFERENCES}

[1] N. Kuzhanova and T. Klets, "Methodological and psychological aspects of education for sustainable development in Russia with regard to international cooperation”: Environment. Technology. Resources: Proceedings of the 11th International Scientific and Practical Conference, June 15-17, 2017, Rezekne, Latvia, vol. I, pp.165-168, http://dx.doi.org/10.17770/etr2017vol1.2559.

[2] S. N. Vodneva, E. A Smirnova, I. I. Khrapchenkova, G. G Maslova, and J. V. Michailova, "Interdisciplinary network project as a factor of the ecologization of youth consciousness" in Lecture Notes in Networks and Systems, vol. 111, 2020, pp. 333-341, DOI: 10.1007/978-3-030-39797-5_34

[3] B. Culiberg and I. Rojšek, "Understanding environmental consciousness: a multidimensional perspective”, in Grbac, B. Meler, M. (Eds.), Vrijednost za potrošače u dinamičnom okruženju, Ekonomski fakultet Sveučilišta u Rijeci, CROMAR Hrvatska zajednica uduga za marketing, Rijeka, 2008, pp. 131-139.

[4] Convention "Agenda XXI: Programme of Action for Sustainable Development,” United Nations Conference on Environment and 
Environment. Technology. Resources. Rezekne, Latvia Proceedings of the $13^{\text {th }}$ International Scientific and Practical Conference. Volume 2, 267-273

Development, Rio de Janeiro, Brazil, 3-14 June, 1992. . [Online]. Available:

https://www.un.org/ru/documents/decl_conv/conventions/agenda2 1.shtml [Accessed: Dec. 17, 2020]

[5] I. A. Khurramov, "Problems of environmental education and upbringing on the example of the world community" in Young scientist, no. 11, 2012, pp. 493-496. [Online]. Available: https://moluch.ru/archive/46/5640/ [Accessed: Oct. 15, 2019]. (in Russian)

[6] S. B. Belova, E. S. Starchikova, and I. Yu. Starchikova, "Influence of environmental theme on the worldview of schoolchildren and students of technical universities when teaching a foreign language” in Perspectives of Science and Education, vol. 35 (5), 2018, pp. 74-81, DOI: 10.32744/ pse.2018.5.8.

[7] D. S. Ermakov, Formation of the ecological competence of students. M.: MIOO, 2009, 180 p. (in Russian)

[8] N. Kuzhanova, A. Dementiev, and T. Klets, "Formation of riskbalanced style of professional activity among university students": Environment. Technology. Resources: Proceedings of the 12 th International Scientific and Practical Conference, June 20-22,
2017, Rezekne, Latvia, vol. I, pp.127-130, http://dx.doi.org/10.17770/etr2019vol1.4034.

[9] L. M. Andryukhina, N. Yu. Fadeyeva, and De Negri Zherar, "Development of the environmental culture of students in the process of intercultural communication in a foreign language" in Education and Science, vol. 19, no. 8, 2017, pp. 47-74, DOI: 10.17853/1994-5639-2017-8-47-74.

[10] T. Klets, O. Malysheva, N. Presnyakova, and M. Starovoitova, "The development of a bachelor's soft skills through project activities in a foreign language": Society. Integration. Education: Proceedings of the International Scientific and Practical Conference, May 22-23, 2020, Rezekne, Latvia, vol. V, pp. 459470, http://dx.doi.org/10.17770/sie2020vol5.5010.

[11] T. Lindhqvist, "Mot ett förlängt producentansvar — analys av erfarenheter samt förslag" ("Towards an Extended Producer Responsibility - analysis of experiences and proposals”), published by the Ministry of the Environment and Natural Resources ini "Varor som faror - Underlagsrapporter" ("Products as Hazardous - background documents”), April, 30"th 1992. (in Swedish) 